\title{
TRIAGEM IN VITRO DE ATIVIDADE ANTIFÚNGICA DE ÓLEOS ESSENCIAIS SOBRE LEVEDURAS DE CANDIDA COMO ESTRATÉGIA DE PROSPECÇÃO E RACIONALIZAÇÃO DO USO DE FITOTERÁPICOS
}

Letícia Pinheiro de Melo, Universidade Federal de Campina Grande (UFCG), leticia.pinheiro.melo@gmail.com

Alex de Novais Batista, Universidade Federal de Campina Grande (UFCG) alexnovaisb@gmail.com

Giliara Carol Diniz de Luna Gurgel, Universidade Federal de Campina Grande (UFCG), giliara.carol@ufcg.edu.br

\section{IN VITRO SCREENING OF ESSENTIAL OILS' ANTIFUNGAL ACTIVITY ON CANDIDA YEASTS AS A STRATEGY TO PROSPECT AND RATIONALIZE THE USE OF PHYTOTHERAPICS \\ ABSTRACT}

This article shows the antifungal properties of eight essential oils extracted of plants widely known by the Brazilian popular knowledge. This is a prospective experimental study and for its execution, it was done a qualitative antibiogram with ten strains of Candida spp and essential oils. The inhibition zones varied among $9,4 \mathrm{~mm}$ to $24,9 \mathrm{~mm}$. This study demonstrates the importance of efficient and accessible therapies as an alternative to the unreasonable use of synthetic medicines.

KEYWORDS: Phytotherapy; Candida; essential oils;

\section{EL ENSAYO IN VITRO DE ACTIVIDAD ANTIFÚNGICA DE ACEITES ESENCIALES SOBRE LEVADURAS DE CANDIDA COMO ESTRATEGIA DE PROSPECCIÓN Y RACIONALIZACIÓN DEL USO DE FITOTERÁPICOS}

\section{RESUMEN}

Este artículo pretende evidenciar las propiedades antifúngicas de ocho aceites esenciales extraídos de las plantas, siendo estas ampliamente conocidas por el saber popular brasileño. Esta investigación es de carácter experimental con realización de antibiograma con cepas de Candida spp y aceites esenciales. Esta investigación muestra la importancia de terapias eficaces y accesibles como una alternativa frente al uso indiscriminado de medicamentos sintéticos.

PALAVRAS CLAVES: Fitoterapia; Candida; aceites esenciales; 


\section{RESUMO}

A fitoterapia é explorada desde os primórdios da humanidade, contudo, esses saberes foram substituídos devido à falta de comprovação científica dessas propriedades e com o surgimento de medicamentos sintéticos. Esse artigo visa evidenciar as propriedades antifúngicas de oito óleos essenciais extraídos das plantas: alecrim, camomila, canela, cravo, eucalipto, limão, louro, orégano, sendo essas largamente conhecidas pelo saber popular brasileiro. Essa pesquisa é de caráter experimental prospectivo onde foi realizado um antibiograma qualitativo pelo método de difusão em Ágar Sabouraud Dextrose. Foram utilizadas no ensaio 10 cepas de Candida spp e $20 \mu \mathrm{L}$ de cada óleo essencial, incubado a $35^{\circ} \mathrm{C}$. O método utilizado foi escolhido por ser de fácil execução, baixo custo e trazer resultados qualitativos em 24 horas. Os resultados médios dos halos de inibição variaram entre 9,4mm (Ruta graveolens L.) e 24,9mm (Origanum vulgare L.). A amostra de C. albicans LMV42 foi mais sensível à inibição feita pelos óleos e a menos sensível foi a C. krusei ATCC 6258. Logo, com esse artigo, reitera-se a relevante ação fitoterápica e a necessidade da realização de pesquisas na área. Essas pesquisas seriam importantes para o desenvolvimento de terapias eficazes e acessíveis como uma alternativa frente ao uso indiscriminado de medicamentos sintéticos.

PALAVRAS-CHAVE: Fitoterapia, Candida, óleos essenciais.

\section{INTRODUÇÃO}

A utilização da natureza para fins terapêuticos é tão antiga quanto à civilização humana e, por muito tempo, produtos minerais, de plantas e animais foram fundamentais para a área da saúde, pois o homem buscava na natureza recursos para melhorar suas próprias condições de vida, aumentando suas chances de sobrevivência. (BRASIL, 2012; LORENZI, MATOS, 2008).

Até o século XX, o Brasil era um país essencialmente rural, com um amplo uso da flora medicinal, tanto a nativa quanto a introduzida. Em consequência do processo de industrialização e seguinte urbanização do país, o conhecimento tradicional do uso de plantas medicinais passou a ser posto em segundo plano naquela época. $\mathrm{O}$ acesso a medicamentos sintéticos e o pouco cuidado com a comprovação das propriedades farmacológicas das plantas tornou o conhecimento da flora medicinal sinônimo de atraso tecnológico e desacreditado entre a população (LORENZI, MATOS, 2008).

Com o passar do tempo, novas tendências globais de uma preocupação com a biodiversidade, bem como a concepção de um desenvolvimento sustentável trouxeram novos ares ao estudo das plantas medicinais. Ainda neste escopo, foram estabelecidas novas linhas de pesquisa, algumas delas buscando bases mais sólidas para a validação científica do uso de plantas medicinais. Com isto, a Fitoterapia e a Botânica voltaram a ser vistas como aliadas e 
cooperar para a melhoria da qualidade de vida da população brasileira (LORENZI, MATOS, 2008).

Historicamente, as plantas medicinais são importantes como fitoterápicos e na descoberta de novos fármacos, sendo do reino vegetal a maior contribuição quanto ao desenvolvimento de novas opções terapêuticas (BRASIL, 2012). No entanto, o uso de plantas medicinais deve ser embasada em um padrão de segurança e eficácia terapêutica, que de certa forma já tenha sido corroborada mediante testes de comprovação científica ou até mesmo do empirismos e observação à partir do uso pregresso. Para questão de saúde pública, é de suma importância que essas plantas sejam validadas cientificamente, a fim de confirmar a viabilidade de seu uso como recurso terapêutico eficaz e seguro (ROSSATO et al., 2012).

A desinformação em torno das propriedades biológicas das plantas, seu consumo associado à medicação alopática, a falta de conhecimento quanto a sua toxicidade, além da dificuldade de identificação das mesmas pela população, são fatores preocupantes da automedicação por produtos naturais. Por este motivo, desde 1977, a OMS tem incentivado o estudo das plantas conhecidas popularmente como medicinais, com a finalidade de avaliar cientificamente seus benefícios e de conhecer os riscos relacionados ao seu uso (LOGUERCIO et al., 2005).

Ainda que evidenciada a atividade biológica dos fitoterápicos por comunidades, são necessários estudos sobre suas propriedades medicinais e perfil toxicológico para que seja possível a elaboração e o desenvolvimento de novas drogas produzidas por meio dos produtos naturais, bem como, o seu consumo de forma segura pela população.

Desta forma, o presente estudo se propõe a avaliar a atividade antifúngica in vitro do óleo essencial de 08 espécies vegetais largamente conhecidas e utilizadas no Brasil (alecrim, camomila, canela, cravo, eucalipto, limão, louro, orégano), em sua concentração absoluta, sobre leveduras do gênero Candida.

\section{METODOLOGIA}

A triagem ou antibiograma qualitativo para avaliar a atividade antifúngica dos óleos essenciais sobre leveduras do gênero Candida, foi realizado pelo método de difusão em meio sólido. 
Os óleos essenciais submetidos ao ensaio foram fornecidos pela Ferquima Ind. Com. Ltda. (Vargem Grande Paulista, São Paulo, Brasil).

Foram utilizadas no ensaio 10 cepas de Candida spp em repiques recentes de 24-48 horas. Em placas de Petri descartáveis e estéreis, de 90x15mm (DISPO PETRI / INTERLAB), na qual foi dispensada uma alíquota de $01 \mathrm{~mL}$ da suspensão de cada cepa, ajustada ao padrão 0.5 da Escala de McFarland, correspondendo a aproximadamente $10^{6}$ unidades formadores de colônia por mL. Em seguida, adicionou-se $21 \mathrm{~mL}$ de meio sólido fundido (Ágar Sabouraud Dextrose) a $50^{\circ} \mathrm{C}$, sendo todo o sistema homogeneizado lentamente. Após a solidificação do meio de cultura, foram depositados discos de papel de filtro com $06 \mathrm{~mm}$ de diâmetro (CECOH/SP), embebidos com $20 \mu \mathrm{L}$ de cada óleo essencial em estudo, na sua concentração absoluta. Todo o ensaio foi incubado a $35^{\circ} \mathrm{C}$ por $24-48$ horas.

Decorrido o tempo de incubação adequado, foi feita a leitura dos resultados. Os ensaios foram realizados em duplicata e os resultados foram considerados positivos quando a média aritmética dos halos de inibição foi igual ou superior a $15 \mathrm{~mm}$ de diâmetro em, pelo menos, 50\% do total das cepas testadas (CLEELAND,SQUIRES,1991; HADACECK; GREGER, et al.,2000; ALLEGRINI et al., 1973).

\section{DESCRIÇÕES, RESULTADOS, INTERPRETAÇÕES.}

Uma triagem ("screening") de avaliação da atividade antifúngica de produtos naturais, em seu estado puro ou "in natura"é considerado como o ponto de partida laboratorial para a prospecção de vegetais com perfil de bioatividade potencial, proporcionando conhecimento sobre a segurança no uso dos mesmos (AFOLAYAN; MEYER, 1997, BATISTA et al, 1994).

Desde 1972, Mitsher et al, sugerem a triagem microbiológica e reconhecem que a partir deste teste tipo de ensaio, o direcionamento da pesquisa de vegetais aptos ao escrutínio aprofundado de propriedades terapêuticas pode ser otimizado, reduzindo o tempo e os insumos empregados, por direcionar o campo de pesquisa a espécies vegetais com bom desempenho (MITSHER et al, 1972), sendo por isso considerada a metodologia mais adequada para este ensaio. 
$\mathrm{Na}$ execução da triagem ("screening") de atividade antifúngica, foi escolhido o método de difusão em disco, consoante com diversos estudos realizados com esta mesma finalidade (OSTROSKY et al, 2008, RABANAL et al, 2002, TADEG et al, 2005), pelo fato de que este método é largamente utilizado na rotina laboratorial, é de fácil execução, baixo custo e proporciona resultados qualitativos em 24 horas (ESPINELINGROFF, 2007).

Os tamanhos dos halos de inibição de crescimento fúngico, variaram bastante sendo o menor igual a $7 \mathrm{~mm}$ e o maior igual a $32 \mathrm{~mm}$. Entre as médias do halo de inibição o valor mínimo foi de 9,4mm (Ruta graveolens L.) e valor máximo foi de 24,9 (Origanum vulgare L.). Destacaram-se neste ensaio os resultados obtidos pelos óleos essenciais de C. zeilanicum Nees (21,6mm), E. caryophyllata Thunb (23,1mm), E. globulus Labill. (19,4mm) e O.vulgare L. $(24,9 \mathrm{~mm})$, cujas médias aritméticas dos halos de inibição foram superiores a $15 \mathrm{~mm}$.

Quanto ao comportamento das cepas frente à ação dos óleos essenciais, a amostra $C$. albicans LMV42 foi a mais susceptível, apresentando halo de inibição superior a $15 \mathrm{~mm}$ diante de 08 (80\%) óleos essenciais, e cuja média dos halos de inibição resultou em 20,9mm. No que concerne à cepa menos sensível, destacou-se C. krusei ATCC 6258, apresentando apenas 03 (30\%) halos de inibição superiores a 15mm e média dos halos de inibição igual a $12,3 \mathrm{~mm}$.

Achados na literatura sugerem que o teste da ação antimicrobiana dos óleos essenciais seja realizado com isolados múltiplos para cada espécie testada (CHANG et al., 2001; HAMMER et al., 2003), sendo portanto selecionadas para este estudo, no mínimo 02 cepas por espécie. Foram incluídas também cepas de referência (ATCC) com o objetivo de permitir a comparação com estudos semelhantes, nos quais foram testados outros produtos de origem vegetais. Estas cepas são representativas das espécies a que pertencem por ter seu comportamento microbiano vastamente descrito frente a quimioterápicos (antibióticos e/ou antifúngicos) sintéticos convencionais, sendo portanto excelente parâmetro comparativo do desempenho de novos produtos com potencial bioatividade.

Todas as espécies vegetais submetidas ao "screening" foram reportadas previamente como detentoras de propriedade antimicrobiana (ALVES et al, 2000, HOLETZ et al, 2002, KONNING et al, 2004 , LOPEZ et al, 2005). 


\section{CONSIDERAÇÕES FINAIS}

Este estudo confirma a relevância dos dados de levantamentos etnofarmacológicos na seleção de plantas para triagem de atividade biológica, especialmente no tocante à racionalidade no emprego dos mesmos, que já são largamente difundidos enquanto originados de plantas medicinais. A atividade antibacteriana dos óleos testados nesse trabalho pode abrir perspectivas no que concerne à pesquisa e ao desenvolvimento de fitoterápicos ou fitofármacos eficazes e de baixo custo, podendo ser empregados no tratamento das candidoses.

\section{REFERÊNCIAS}

AFOLAYAN, A. J.; MEYER, J. M. The antimicrobial activity of 3,5,7-trihydroxyflavone isolated from the shoots of Helichrysum aureonitens. Journal of Ethnopharmacology. v. 57, p.177-181, 1997.

ALLEGRINI, J.; BOUCHBERG, M.S.; MAILOLS, H. Émulsiond d'huilles essentielles frabricaton et applications en microbiologie. Soc. Pharm. Montpellier, Montpellier, v. 33, p. 73-86, 1973.

ALVES, T.M.A.; SILVA, A.F.; BRANDÃO, M.; GRANDI, T.S.M.; SMÂNIA, E.F.; SMÂNIA, J.R.; ZANI, C.L. Biological screening of Brazilian medicinal plants. Memórias Instituto Oswaldo Cruz. v. 95, p. 367-373, 2000.

BATISTA, O.; DUARTE, J.; NASCIMENTO, A.; SIMONES, M. F. Structure and antimicrobial activity of diterpenes from the roots of Plectranthus hereroensis. Journal of Natural Products. v. 57, p. 858-861, 1994.

BRASIL. Ministério da Saúde. Secretaria de Atenção à Saúde. Departamento de Atenção Básica. Práticas integrativas e complementares: plantas medicinais e fitoterapia na Atenção Básica / Ministério da Saúde. Secretaria de Atenção à Saúde. Departamento de Atenção Básica. - Brasília: Ministério da Saúde, 2012. 156 p.:il. - (Série A. Normas e Manuais Técnicos) (Cadernos de Atenção Básica; n. 31).

CHANG, S.T.; CHEN, P.F.; CHANG, S.C. Antibacterial activity of leaf essential oils and their constituents from Cinnamomum osmophloeum. Journal Ethnopharmacology. v.77, p. 123-127, 2001.

CLEELAND R.; SQUIRES E., Evaluation of new antimicrobials in vitro and experimental

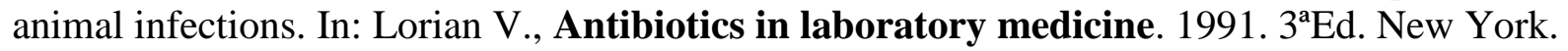

ESPINEL-INGROFF, A., Standardized Disk Diffusion Method for Yeasts, Clinical Microbiology Newsletter. v. 29, n. 13, 2007. 
HADACEK, F.; GREGER, H. Testing of antifungal natural products: methodologies, comparability of results and essay choose. Phytochemichal. Annals. v. 11, p. 137- 147. 2000.

HAMMER, K.A.; DRY, L.; JOHNSON, M.; MICHALAK, E.M.; CARSON, C.F.; Susceptilibity of oral bacteria to Melaleuca alternifolia (tea tree) oil in vitro. Oral Microbiol Immunol. v.18, p. 389-392, 2003.

HOLETZ, F.B. ; PESSINI, G.L.; DIÓGENES, N.R.S.; CORTEZ, A.G.; NAKAMURA, C.V.; DIAS FILHO, B.P. Screenning of some plants used in the brasilian folk medicine for infectious diseases. Memórias Instituto Oswaldo Cruz. v.97, n. 7, p.1027-1031, 2002.

KONNING, G.H.; AGYARE, C.; ENISSON, B. Antimicrobial activity of some medicinal plants from Ghana. Fitoterapia. v. 75, n. 1, p. 65-67, 2004.

LOGUERCIO, A. P.; BATTISTIN, A.; VARGAS, A. C.; HENZEL, A.; WITT, N. M. Atividade antibacteriana de extrato hidro-alcoólico de folhas de jambolão (Syzygium cumini) (L.) Skells. Ciência Rural, v. 35, n.2, p. 371-376, 2005.

LOPEZ, P.; SANCHEZ, C.; BATLLE, R.; NERIN, C.; Solidand vapor-phase antimicrobial activities of six essential oils: susceptibility of selected foodborne bacterial and fungal strains. Journal of Agriculture, Food and Chemistry. v.53, n. 17, p. 6939-6946. 2005.

LORENZI, H.; MATOS, F. J. A.. Plantas medicinais no Brasil: nativas e exóticas. 2. ed. São Paulo: Instituto Plantarum, 2008. 544 p.

MITSHER, L.A., LEU, R.P., BATHALA, M.S. Antimicrobial agen ts from higher plants I Lloydia. v 35, n 2, p.157-66, 1972.

OSTROSKY, E.A.; MIZUMOTO M.K.; LIMA, M.E.L.; KANEKO, T.M.; NISHIKAWA, S.O.; FREITAS, B.R. et al. Métodos para avaliação da atividade antimicrobiana e determinação da Concentração Mínima Inibitória (CMI) de plantas medicinais. Revista Brasileira de Farmacognosia. v. 18, n.2, p. 301-307, 2008.

RABANAL, R.M.; ARIAS, A.; PRADO, B.; HERNÁNDEZ-PÉREZ, M.; SÁNCHEZMATEO, C.C. Antimicrobial studies on three species of Hypericum from the Canary Islands. Journal of Ethnopharmacology. v. 81: p. 287-292, 2002.

ROSSATO, A. E. (org.) et al.. Fitoterapia Racional: aspectos taxonômicos, agroecológicos, etnobotânicos e terapêuticos. Florianópolis: DIOESC, 2012. 211 p.

TADEG, H.; MOHAMMED, E.; ASRES, K.; GEBRE-MARIAN, T. Antimicrobial activities of some selected traditional Ethiopian Medicinal plants used in treatment of skin disorders. Journal of Ethnopharmacology. v. 100, p. 168-175, 2005. 